\title{
ENTREVISTA A ISABEL VERdeJO, COMPAÑERA Y ESPOSA DE RaMón GaYa
}

1) En la vida de Ramón Gaya hay una fractura antes y después del exilio, y una división entre el primer exilio mexicano y el segundo en Italia. ¿Cómo sentía este pasado Ramón cuando usted lo conoció?

Sí, son dos épocas muy diferentes en la vida de Ramón Gaya. Gracias al ofrecimiento del presidente Cárdenas algunos republicanos españoles pudieron refugiarse en México tras la guerra en España. Gaya fue uno de ellos. En su caso, no sólo había perdido la guerra, como sus compañeros de infortunio, sino que, en los últimos días de la contienda, en el bombardeo de la estación de Figueras a la población civil, había caído herida de muerte Fe Sanz, su primera esposa. Alicia, su pequeña hija, se salvó y fue rescatada por Carmen Muñoz, la esposa de Rafael Dieste, que viajaba con ellas.

Gaya llegó a México destrozado. Le costó mucho volver a encontrar la paz interior necesaria para pintar y escribir. Pero poco a poco, gracias al apoyo de un pequeño grupo de amigos, fue haciéndose al ritmo de la vida mexicana, empezó a colaborar con sus escritos en algunas revistas locales y a pintar. En 1943 hizo una exposición de su pintura, con un texto de Juan Gil-Albert en el catálogo: «Continuación de la pintura». También Octavio Paz le dedicó un escrito a su exposición, «Realismo y poesía», publicado el día 26 de mayo de 1943 en el Novedades de México. Hoy conocemos la mayor parte de sus pinturas de aquellos años y tenemos a nuestro alcance prácticamente todos sus escritos.

En México, en aquella época, era prácticamente imposible contemplar directamente un cuadro de Tiziano, de Tintoretto o de Velázquez... por ejemplo. No existían museos dedicados a los Clásicos. Gaya empezó a comprar monografías y estampas de sus pintores predilectos, con el fin de estar rodeado de esa pintura que amaba y para que su pintura pudiera evolucionar. De ahí, de ese contacto permanente con los clásicos, empezaron a nacer sus «Homenajes», como una puesta en valor, en voz baja, de los grandes pintores.

En 1950 volvió a hacer otra exposición, en este caso en el Ateneo Español. El poeta Xavier Villaurrutia publicó en el Excelsior un artículo sobre «Los óleos de 
Ramón Gaya». En mayo de 1951 la antropóloga Laurette Sejournée publicó en Las Españas «Ramón Gaya», un artículo sobre su pintura.

Poco después, tras once años en México, empezó a valorar la idea de volver a Europa. Deseaba, sobre todo, visitar Italia y sus museos. París lo conocía, había pasado allí seis meses en 1928, y hasta hizo una exposición en Les Quatre Chemins con mucho éxito.

Se puso de acuerdo con su gran amiga Concha de Albornoz, convocaron a Clarita James, exalumna y amiga de Concha, que había visitado Italia el año anterior, y a su común amigo Juan Gil-Albert, que ya se encontraba en España.

Ramón Gaya permaneció en Europa un año, de junio de 1952 a junio de 1953. Durante los dos primeros meses el grupo de amigos recorrió Italia de norte a sur: de Venezia a Paestum. Cuando se despidió de ellos viajó a París y a Lisboa, para reencontrase con su hija que vivía allí con Trinita Japp, la viuda de Cristóbal Hall. El 20 de enero de 1953 lo encontramos de nuevo en Venezia, donde permanecerá hasta el 4 de abril. Es allí, en Venezia, donde tuvo una especie revelación: «Un atardecer, de entre aquellas aguas espesas, usadas, me pareció ver salir, surgir como una Venus cochambrosa, el manchado cuerpo de la Pintura», anotó en El sentimiento de la pintura.

Durante este año que pasa en Europa siente que debe volver, pero para varios años, o para siempre. Tanto su obra como su espíritu lo necesitan.

Todas las pinturas realizadas durante el viaje tuvieron mucho éxito entre sus amigos de México. Tomó pues la decisión de pintar y vender sus obras, pensando en un futuro viaje a Europa.

2) Venecia y Roma son las dos ciudades italianas elegidas por Gaya para volver a Europa. En sus textos leemos su fascinación por la Venecia de Tiziano; sin embargo, finalmente se instaló en Roma. Además del coste de vida, ¿hubo otras razones?

El 22 de marzo de 1956, Ramón Gaya se halla de nuevo en París, esta vez viene acompañado del poeta Tomás Segovia, y ha convocado de nuevo a su amigo el poeta valenciano Juan Gil-Albert, que acude presuroso a disfrutar de unos días en París con sus viejos amigos. Juan Gil-Albert no puede continuar el viaje con ellos y, pasados unos días, regresa a Valencia. Tomás Segovia y Ramón Gaya continúan su viaje; visitarán Venezia, Florencia y Roma. Allí se reunirán con María Zambrano, su gran amiga. Poco después Tomás debe regresar a México. Desde los primeros años en México, Ramón y María no se habían visto pero habían intercambiado algunas 
cartas; en una de ellas se duelen profundamente por la muerte del gran amigo común, el pintor inglés Cristóbal Hall.

María había conocido a Ramón, según declaró ella misma, en 1932, en los días en que Ramón empezaba a colaborar con Misiones Pedagógicas. Él asistió en alguna ocasión a las tertulias que María organizaba en casa de sus padres en la plaza del Conde de Barajas de Madrid. Inmediatamente había surgido entre ellos una gran admiración y simpatía.

A pesar de su juventud, Ramón no sólo había realizado nueve copias de cuadros del Prado, para el museo ambulante de Misiones Pedagógicas, sino que aceptó viajar con el Museo por los pueblos de España. En 1935, en Cuevas de Almanzora, conoció a Fe Sanz, profesora de instituto; se volvieron a ver en Madrid y se prometieron. Se casaron el 24 de junio de 1936. Fe Sanz era gran amiga de María y compañera de Universidad. Compartir un profundo dolor por su muerte al final de la guerra creó entre Ramón y María un vínculo muy profundo.

Ramón había pensado en un primer momento alquilar un estudio en Venezia; recordemos lo fructíferos que resultaron para él, como pintor y como escritor, los casi tres meses que pasó allí en 1953. Allí tuvo la revelación de la que antes hablé y en aquellos meses comenzó a escribir El sentimiento de la pintura.

Pero tener un pequeño estudio en Venezia, no siendo veneziano, se le reveló como algo prácticamente imposible; las casas eran grandes y había que empezar por acondicionarlas. No disponía del tiempo ni del dinero necesarios. Para sus estancias en Venezia se serviría siempre de pequeños hoteles bien situados.

Decidió pues establecerse en Roma. Además, allí contaba con la presencia de las hermanas Zambrano. Alquiló un estudio en via Margutta, muy cerca de donde vivían sus amigas, que en aquella época residían en Piazza del Popolo. Durante los primeros tiempos María y Ramón se veían casi a diario, salían a cenar en alguna de las «trattorías» del barrio y hablaban de lo humano y lo divino. Ramón ha declarado en alguna ocasión que leer a María era un gozo y una gran enseñanza, pero que escucharla de viva voz, sin público, ellos dos solos, era una experiencia indescriptible.

Gracias a María conoció muy pronto a Elena Croce y a Tomaso Carini, su compañero. Las hermanas Croce como herederas intelectuales de su padre, el gran Benedetto Croce, eran respetadísimas en Italia. Elena, en su casa de Roma, organizaba encuentros entre escritores y artistas italianos y extranjeros de paso o residentes en Roma. Ramón asistió muchas veces a esos encuentros. Allí encontró a algunas de las figuras más relevantes de aquella época. 
3) En los años 60 y 70 Roma acogió a muchos intelectuales españoles: las hermanas Zambrano, Enrique de Rivas, Tomás Segovia, Diego Mesa $y$ muchos otros. Las relaciones entre ellos, y con los artistas italianos, marcó una época feliz de redescubrimiento de la cultura española en Italia. ¿Cómo describiría aquel ambiente? ¿Qué vivencias dejaron más huella en usted y Ramón?

Aunque Gaya acudía con gusto a aquellos encuentros, por sus cartas sabemos que se ausentaba de Roma cada dos o tres meses. Tras más de quince años en México, sentía una necesidad casi física de ver pintura. Uno de sus destinos más frecuentes era París; allí se citaba en alguna ocasión con su hija, Alicia, que seguía viviendo en Lisboa. A veces se quedaban allí, para visitar exposiciones y asistir a conciertos, y en otras ocasiones pasaban unos días en Venezia.

En 1957 coincidió unas semanas con María Zambrano en Florencia, pues ambos se encontraban allí para trabajar. Por sus cartas sabemos que se citaban para el almuerzo y la cena, y el resto del tiempo lo reservaban para su obra.

Durante los cuatro años que van de 1956 a 1960 Gaya visitó varias veces las ciudades europeas, incluyendo las italianas, para contemplar pintura.

Había conocido también al resto de las hermanas Croce. Estuvo más de una vez en Nápoles, en el «santuario Croce», invitado por ellas. De ese grupo familiar quiero destacar a Leonardo Cammarano, marido de Silvia en aquella época. Con él se estableció de por vida una gran amistad basada en la cordialidad y la simpatía mutuas. Cammarano, escritor y traductor, es además pintor. Y como él ha relatado en alguna ocasión, salieron a pintar juntos por los alrededores de Nápoles. Es también el primer traductor al italiano de Gaya. En 1960 tradujo, para Quaderni di pensiero e di poesia, El sentimiento de la pintura; y en 1971, para el número I de Conoscenza Religiosa, la revista fundada por Elémire Zolla, Velázquez, pájaro solitario.

Entre las personas que Ramón conoció por medio de Elena Croce, citaré sobre todo a las que tuvieron mayor presencia en su vida, tanto por la amistad y simpatía que le manifestaron, como por la coincidencia en sus gustos artísticos e intelectuales. Alba Buitoni Gatteschi fue una gran amiga de Ramón Gaya. Fundadora de Gli amicci della musica di Peruggia, un proyecto al que se dedicó durante años con gran pasión y eficacia. Era respetadísima por su gran talento. Gaya llegó a asistir a alguno de los conciertos celebrados bajo su patrocinio. Gracias a ella conoció a su hija Isabella Buitoni y al marido de esta, el abogado Vittorio Ripa di Meana, grandes amigos de por vida y muy vinculados también con la música. Vittorio Ripa di Meana y Giuseppe Sinopoli fundarían en 1985 la Associazione Amici di Santa Cecilia, de Roma. Con ellos compartió Gaya su gran amor por la música. También conoció en 
el salón de la Croce a Nicola Chiaromonte. Gaya sintió por él un profundo respeto y se citaron en alguna ocasión para charlar en la sede de Tempo Presente, la revista de política y de arte fundada en 1956 por él y por Ignazio Silone.

En el caso de Pietro Citati, Cristina Campo y Elémire Zolla, no sólo se habían saludado en alguna ocasión en casa de Elena Croce, sino que los tres se sintieron muy atraídos por el «librito» de Gaya, recién traducido al italiano por Cammarano: El sentimiento de la pintura. Y los tres lo recibieron dedicándole páginas muy certeras y elogiosas. Pietro Citati lo hizo en «Letteratura e arte» para Il Giorno, en Roma en el año 1960: «[...] Gaya es verdaderamente uno de los ensayistas y moralistas más vivos y libres que nos es dado leer hoy...».

Elémire Zolla publicó «La pittura ed il nulla» en La Gazzetta del Popolo, Torino, 28 de mayo de 1960: «[...] El discurso de Gaya es candente y sosegado, una lúcida exaltación; pertenece a la estirpe de esos hombres indemnes a la cultura de masas...».

Y el caso de Cristina Campo es el más misterioso: le escribe a Leone Traverso con gran entusiasmo y le pide que escriba también sobre Il Sentimento della pittura. Le dice: «Tras la muerte de Pasternak, descubrir a Gaya ha sido un gran consuelo para mí». Del original del artículo que escribió Cristina Campo sobre El sentimiento de la pintura he sabido últimamente que no se encontraba entre los papeles catalogados de ella. Cristina se lo había regalado a Gaya y se encuentra entre los documentos que él conservó de por vida.

También conoció y trató a Giacomo Manzú. Lo visitó en alguna ocasión en su estudio. Fue el escultor contemporáneo más admirado por Gaya. Conservamos algún catálogo dedicado y seis misivas autógrafas de Manzú.

Otro escultor también muy admirado por Gaya fue Carmelo Pastor, español, becario de la Accademia di Spagna, muerto prematuramente. Se lo presentó María Zambrano, pertenecía también al entorno de las hermanas Croce. Se conserva una cabeza de Gaya modelada por él, sumamente sensible y de un gran parecido. Conservamos una colección de fotos de Ramón Gaya en Roma, tomadas por Carmelo Pastor en 1958 y por Giovanna, su esposa.

En marzo de 1960, tras veintiún años de exilio, Gaya regresa a España. Sus amigos españoles le han organizado una exposición en la Galería Mayer de Madrid. María Zambrano ha escrito un texto decisivo sobre su pintura que aparecerá publicado en Índice; José Bergamín leerá unas palabras de bienvenida en la inauguración. En Ediciones Arión, la editorial dirigida por Fernando Baeza, aparece la versión española de El sentimiento de la pintura. Gaya tuvo la gran fortuna de volver a encontrar a viejos amigos. Alicia, su hija, acudió desde Lisboa.

Gaya aceptó con gusto esta iniciativa porque desde que llegó a Italia, aunque había seguido pintando con asiduidad tanto en su estudio como en exteriores, salvo 
los amigos más íntimos como las hermanas Zambrano, las Croce y pocos más, nadie conocía sus cuadros; a Ramón Gaya se le consideraba escritor: poeta y ensayista.

También sus amigos catalanes le proponen mostrar sus cuadros en la Galería Syra, de Barcelona, antes de volver a Roma. Esta exposición tuvo mejor acogida.

El 3 de agosto Gaya le escribe a María: «Sólo unas líneas para decirte que recibí tu carta. [...] Sí, dile a Elena [Croce] que yo volveré a Roma sin falta...».

En 1961, volvió a España para participar en el Congreso sobre Velázquez celebrado en Málaga, al que había sido invitado por los organizadores, y tuvo la ocasión de visitar el campo andaluz. Pero siguió viviendo en Roma; ahora lo encontramos en un pequeño ático de Via del Babuino. Sin embargo solía pasar una parte del verano en España, con pequeñas estancias en Murcia, Valencia, Madrid, Barcelona, Cuenca... Poco a poco fue abriéndose paso en España como pintor y empezaban a llegar nuevos amigos.

En 1965, en Milán, le conceden por su Velázquez, pájaro solitario, exaequo con Mauro Senesi, el premio Inedito.

En 1968 y 1969, tuvo dos percances de salud, el primero grave y el segundo menos grave. En ambos casos tuvo que ser operado por su gran amigo el doctor Barros en Madrid.

En 1969, en la editorial RM de Barcelona, apareció la edición definitiva de su Velázquez, pájaro solitario, acogida con entusiasmo con artículos de Juan GilAlbert, Antonio Sánchez Barbudo, Rafael Santos Torroella... Su «Velázquez» sigue deslumbrando a los lectores cincuenta años después.

En 1971, tuvo la ocasión de comprar un pequeño estudio en Roma, en el Vicolo del Giglio, junto a Piazza Farnese y Campo di Fiori, que conservó de por vida. Por primera vez disponía de un estudio propio. Lo amuebló con esmero y buen gusto, poniendo mucha atención a la hora de escoger los muebles y los objetos de los que se iba a rodear.

En Madrid, en la Galería Multitud, tuvo lugar en 1978 una gran exposición de su obra. Desde 1960 en la Galería Mayer, no había vuelto a mostrar sus cuadros en Madrid. La exposición tuvo muy buena acogida. Se produjo el verdadero encuentro del Gaya pintor con el público español.

Comienza su relación con Isabel Verdejo, que se convertirá en segunda esposa.

Giorgio Agamben, a quien Ramón había conocido en Madrid gracias a José Bergamín, le propuso la posibilidad de utilizar el estudio de Vicolo del Giglio, para trabajar, durante los meses que Gaya no se encontraba en Roma. Luego de muchas dudas, Gaya aceptó la propuesta de su amigo, pero reservándose la utilización del estudio siempre que visitara Roma con su mujer. 
El estudio era verdaderamente acogedor y silencioso y Agamben declaraba sentirse muy bien en él. Le propuso varias veces alquilarlo o comprarlo, pero sus propuestas no tuvieron éxito. Gaya deseaba conservar el estudio a su plena disposición, considerando a Agamben como su invitado.

Agamben se lo agradeció participando en varias publicaciones dedicadas a homenajear a su amigo. Ya en 1978, en el número 2/3 de Prospettive Settanta, Roma, tomó parte en el «Omaggio a Ramón Gaya» que se le dedicaba en dicha revista. Tradujo los sonetos (II-II-IV del Pintar) y los acompañó de un ensayo sobre su poética. En 1980 participó en el Homenaje a Ramón Gaya, publicado en Murcia por la Editora Regional, con el ensayo: «Il luogo della poesia: lettura di un soneto di Ramón Gaya» (traducción de Tomás Segovia). En 1995, en Roma, para el catálogo de la exposición de Gaya que tuvo lugar en la Accademia di Spagna, participó con el ensayo: «In luogo del poema», traducción de Tomás Segovia.

Y finalmente llega «El lugar de la poesía. Aproximaciones a la poesía de Ramón Gaya», traducción de Tomás Segovia, para el catálogo de la exposición Ramón Gaya. La hora de la pintura (julio-septiembre 2006), La Pedrera, Fundació Caixa de Catalunya, Barcelona, 2006.

A la muerte de Ramón Gaya, el estudio de Roma pasó a ser propiedad de su hija Alicia.

El 10 de octubre de 1990 había tenido lugar la inauguración en Murcia de un Museo dedicado a su obra.

María Zambrano le envió una felicitación con estas palabras:

«Ramón: me alegro de veras porque aparezcas en tu tierra, en la finura del mundo; como te dije una vez hace siglos: Murcia es lo más fino que he visto. Y así nos entendimos. Hoy te lo escribo como puedo».

María 
